\title{
Malpractice and medical litigation
}

\section{Concezio Di Rocco}

Published online: 13 August 2010

(C) Springer-Verlag 2010

Never as yet have I gone astray, whether in treatment or in prognosis, as have so many other physicians of great reputation...

Galen

Patient-doctor relationship has become complex and medical litigation appears to be a "modern" feature of such a relation.

Indeed at the time of this editorial, a search in Google using the terms "medical litigation" generates 2,270,000 results! The cost of medical litigation has steadily increased at almost $12 \%$ annually since 1975 in the USA and most likely with similar rates in all Western countries. Malpractice has both direct and indirect costs which have been calculated in 2003 by the US Department of Health and Human Services to account for $2 \%$ (direct costs of medical malpractice) of the nation's health-care spending and for $5-9 \%$ of overall expenses when the costs of defensive medical practices are taken into consideration. The adverse impact of defensive medicine include not only unnecessary costs which, however, limit the access to care for certain patients or over and under treatment of the most severe illnesses but also delayed adoption of medical advancements. Actually, the threat of a law suit may discourage the physician and, in particular, the surgeon to use new pharmaceutical and medical devices to avoid the possible accusation of "learning" on the patient.

C. Di Rocco $(\square)$

Pediatric Neurosurgery, Catholic University Medical School,

Largo A. Gemelli, 8,

00168 Rome, Italy

e-mail: cdirocco@rm.unicatt.it
Even though we might incline to consider medical litigation a relatively new phenomenon, supposedly unknown in the past when the doctor-patient relationship was essentially a fiduciary relation, the possibility for a physician to be charged with malpractice was not probably so rare. Competence and eventually experts' support in tribunal constituted, like today, the most effective defensive tools as it may be deduced when reading the comments and the suggestions made by Galen in his preferred book: ANATOMIKAI IГXEIPH $\Sigma$ EI $\Sigma$ (Anatomicae administrationes) (Fig. 1):

"I know about one of those who operate foolishly.... by utilizing the scalpel without reserve on the region of the medial contour of the anterior muscle (m.biceps brachii) where the third nerve (n.radialis) enters, with foolish self-assurance as Hippocrates was used to say, and with a unique and rapid circular cut he sectioned not only the third nerve (n.radialis) but also the first two nerves (nn.musculocutaneous, medianus) and, besides these, also the artery and the vein (which actually lie in the same location). At that moment scared because of the hemorrhage, he took care only of the blood loss by applying tourniquet. A little later, the patient could not move a part of his arm neither he could perceive his limb to be touched and shouted at the physician: "Me miserable, you cut my nerves!".... ...(to avoid such mistakes) you must dissect the arm of a monkey several times with a great accuracy. Even though you will discover something noticeable very rarely, these procedures will be still quite useful. Actually, once, by dissecting a monkey I noticed a small nerve along the internal vein of the elbow (v.basilica). Such an observation resulted to be very 


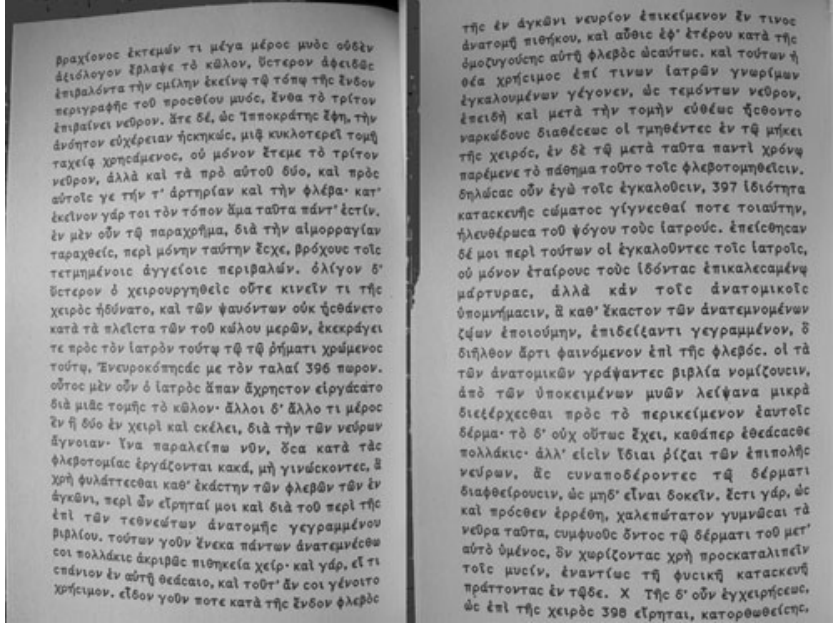

Fig. 1 The Liber Tertius, XI, 396-397 of Claudius Galenus A $\gamma \alpha \tau o \mu \iota k \alpha \iota \varepsilon \gamma \chi \varepsilon \varepsilon \rho \eta \sigma \varepsilon \iota \sigma$ is devoted at demonstrating the importance of the anatomy of the limbs with special emphasis on the vessels and the nerves for the correct surgical practice. In particular, the text reported in this figure (also used as cover figure) illustrates the possible anatomical variants, accounting for some unexpected surgical complications for which a surgeon might be blamed

useful for some known physicians who had been accused of having cut a nerve wrongly in some persons who had experienced a numbness of the arm just after having undergone a longitudinal cut for a phlebotomy. By revealing to the prosecutors that the anomalous position of the nerve could be a variant of the normal structure of the body, I could free these physicians of the blame. The physicians' prosecutors were convinced not only because I called to testify some of my companions who had noticed the (anomalous) nerve together with me but also because I showed them what I had written in my anatomical commentaries during the dissection of each animal and explained what I had seen on the vein".

Galen (Fig. 2) was born in Pergamon, a Greco-Roman town in Asia Minor, in 129 or $130 \mathrm{AD}$ from an affluent and farsighted father, Aelius Nicon, who provided him the best education. According to the tradition, he initiated the son into the medical art after having received an order by Asclepius, the god of medicine, during a dream. Most of Galen's studies were devoted to anatomy, firstly in Pergamon and then after the death of his father, in Smyrna (today, Izmir, Turkey) and Alexandria (Egypt). In 157, he returned in Pergamon where he was appointed physician to the gladiators. Consequently, in the following 4 years he had the opportunity to gain theoretical and practical experience in traumas (Galen is regarded as the father of sports medicine) and in the physiology of the bones related muscles and nerves.

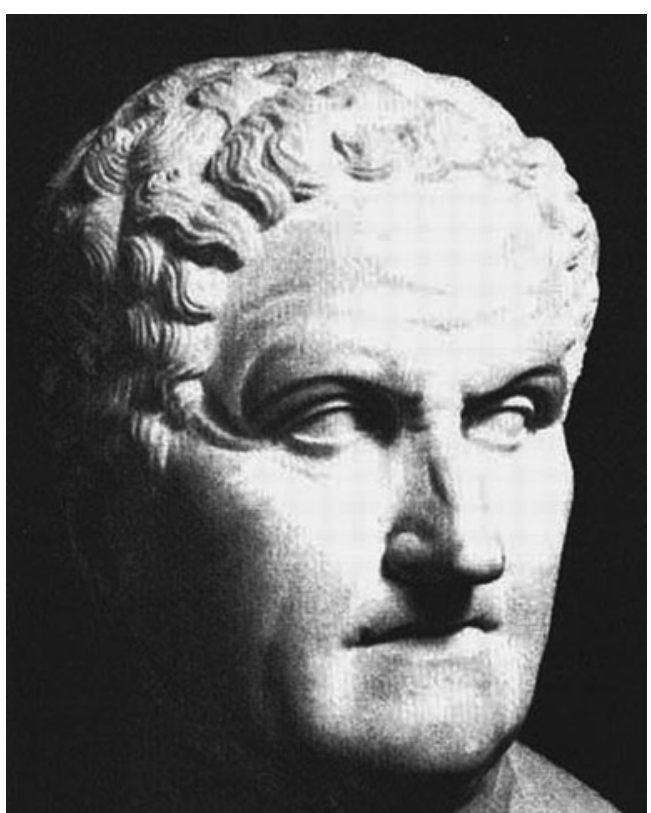

Fig. 2 Claudius Galenus

In 161 or 162 , Galen was in Rome at the beginning of Marcus Aurelius' empire. He was used to give impressive anatomical demonstrations during vivisection experiments to illustrate the functions of the body and the structures involved, in particular those related to the respiration and the emission of the voice and sounds (Fig. 3). He wrote innumerable anatomical descriptions and commented on the anatomical knowledge of his predecessors, namely Hippocrates, Herophilos, and Erasistratos, often being in dispute with his colleagues. During his first Roman period (161-166), he also wrote booklets for students on the anatomy of the bones, arteries and veins, and nerves, which he completed and corrected during his second stay in Rome, from 169 to his death, presumably in 217 AD. One book addressed the symphyses, the sutures, and the foramina of the skull specifically. Nowadays, the approximate 20,000 pages of Galen's treatises which came down to us represent half of all Greek medical literature. Further pages, lost in the Greek version, are available in Latin and Arabic translations. Galen considered himself a philosopher-physician. It is a pity that most of his philosophical ad ethical works are entirely lost.

ANATOMIKAI ITXEIPH $\Sigma$ EI $\Sigma$ (Anatomicae administrations) is the most important anatomical work of Galen, of which only the first eight books in Greek survived; the remaining of the work is known to us through the Arabic translations made by the pupils of Hunain, Hubaish, and Isa at the end of the ninth century. In 192, a fire in the Temple of Peace destroyed several of Galen's books, including the Anatomicae Administrationes. Galen could not find any copy of the books XII-XV among his friends. Therefore, he 
Fig. 3 Panel of the title page of the Galen collected works published in Venice in 1586 showing Galen during one of his public anatomicae administrationes on a living animal

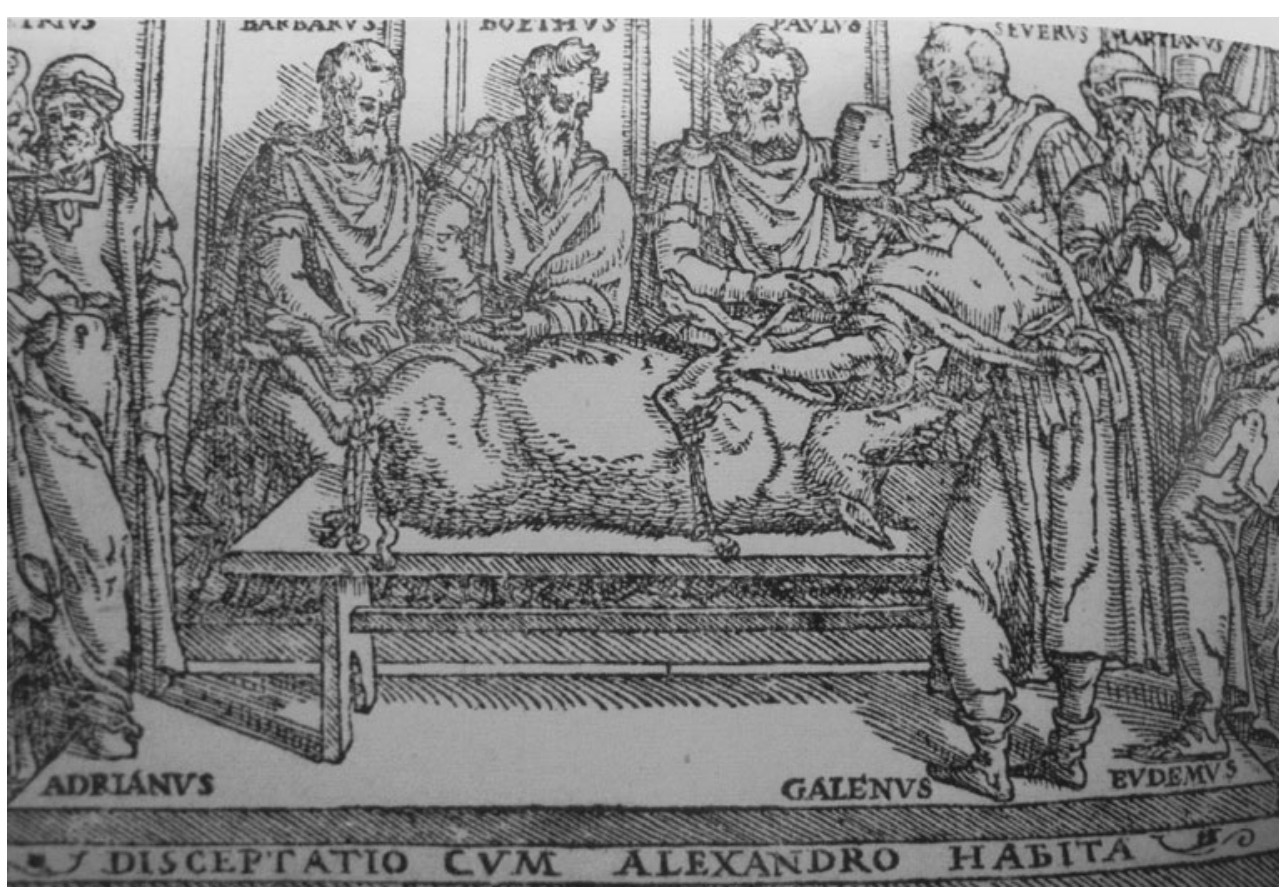

was compelled to re-write them, a task to which he dedicate his efforts until quasi his death.

The anatomical proceedings are the reports of numerous experiments on living animals (to investigate functions) and dissections on dead animals (aimed at illustrating the anatomy). Among the first, the section of the spinal cord to demonstrate the effect on the respiration and the resection of the recurrent nerve to demonstrate the induction of hoarseness are the most known. The dissections of corpses, which interested the entire animal's body, followed a rigorous pattern dictated by the perishability of the structures: muscles and vessels, nerves and viscera, fat tissues and glands.

Galen identified the different beneficiaries:

1. The philosopher, the pure investigator of the nature, the $\phi \cup \sigma$ เKOS

2. The philosopher teleologist that will utilize the observations to demonstrate the finalism of the nature
3. The physician who will use the anatomy as premise to understand the physical functions and the diseases secondary to functional dysfunction

4. The surgeon willing to operate "on surface" correctly

Consequently in Galen's opinion, the surgeon was required only the minimal level of knowledge necessary to avoid mistakes when using the scalpel on the superficial tissues (although excellent operations were made at his times, such as those concerning the eye). The physician was required a further level that is the understanding of the internal anatomy. The optimus medicus, however, should have learned anatomy not only for the surgical practice or for understanding the physiology and recognizing the disease but also for realizing the finalism of the nature and finally to enjoy the pure contemplation, in other words he should have become through the study of anatomy the physician-philosopher like he indulged to consider himself. 